\section{Culture-bound syndromes:}

\section{the story of dhat syndrome}

\author{
A. SUMATHIPALA, S. H. SIRIBADDANA and D. BHUGRA
}

Culture-bound syndromes have been discussed under a variety of names and are defined as 'episodic and dramatic reactions specific to a particular community locally defined as discrete patterns of behaviour' (Littlewood \& Lipsedge, 1985). However, Hughes (1996) proposed that these form a unique and distinctive class of generic phenomena, and that such syndromes exist among and afflict only the 'others' - people who by some criterion are outside the 'mainstream' population (however defined). These syndromes have sometimes been included in discussions of cultural psychiatry (Haldipur, 1980; Murphy, 1977), and the latter authors both argue that this approach is a relic of an imperialist Eurocentric heritage in which these syndromes have become institutionalised in the classificatory systems.

Hughes (1996) raises the point that in order to establish the ontological status of culture-bound syndromes, phenomenologists need to go beyond the semantic difficulties of 'label grip' - the paralysis of analytic acumen often created by powerful diagnostic labels. In his opinion, the generic differences between culture-bound and non-culture-bound syndromes need to be explored. Case data are helpful for this purpose, as are historical analyses of how these symptoms came to be recognised as pathological. In this paper we aim to provide a review of both historical and empirical data.

Psychiatry, too, has suffered from the impact of both imperialism and colonialism, not only through the suppression of indigenous systems of medicine, but also through the imposition of new clinical categories and diagnoses, thus medicalising many forms of stress.

\section{Definitions}

Culture-bound syndromes were seen as causing little damage to humanity, although they might cast light on important but little-understood aspects of human functioning (Murphy, 1976). These syndromes were considered to be rare and exotic: they consisted of unpredictable and chaotic behaviours, and the sufferers were seen as uncivilised. By placing such syndromes in the context of Western diagnostic systems any links between cultural beliefs, environmental stressors and symptoms were often ignored (Bhugra \& Jacob, 1997).

In an interesting overview, Hughes \& Wintrob (1995) recommended that the conceptual frame of reference needs to be expanded if the clinical significance of culture-bound syndromes is to be understood. As these syndromes often cut across diagnostic categories, it is possible that they offer another way of assessment so that clinicians can attempt to understand alternative explanatory and folk models of healing and caring. Furthermore, by placing these conditions in the context of the whole spectrum of disease and normality, these conditions may be dealt with in a more appropriate - perhaps medical - manner.

Yap (1962) recommended that the variety of terms used to describe these syndromes be replaced by the description 'atypical cultural bound psychogenic psychosis', which he subsequently abbreviated to 'culture-bound syndrome' (Yap, 1969). More than 30 years later, the time has come to re-evaluate this condition.

\section{Western culture-bound syndromes}

Interestingly, although for a long time Western psychiatry viewed culture-bound syndromes as essentially Eastern, attention has now been drawn to the culture-bound syndromes of the West. Hughes (1996) identifies the type A behaviour pattern as one such syndrome, characterised by feelings of chronically struggling against time, frustration at failing to achieve goals, hyperaggression and ambition, and impatience in interpersonal relationships; similarly, Littlewood (1996) has described bulimia nervosa as a Western culturebound syndrome. However, both type A personality and variants of bulimia nervosa have been reported from other parts of the world. Culture-bound syndromes have also been equated with ethnic psychosis and ethnic neurosis (Devereux, 1956), hysterical psychosis (Yap, 1969), and rare, unclassifiable collective and exotic syndromes (Arieti $\&$ Meth, 1959). The myriad of titles given suggests that from the beginning the nosology of these syndromes has been 
problematic. The use of the suffix 'bound' to illustrate the restriction of these syndromes to individual cultures is itself fraught with difficulties. Therefore, the suggestion by Mezzich et al (1996) that culture-bound syndromes illustrate the importance of using an anthropological framework in diagnosis becomes an important one.

Hughes (1985) observed that the labels 'atypical psychosis' and 'exotic syndrome' imply deviance from a standard diagnostic base; 'exotic' becomes foreign, exciting, deviant or different, strengthening the notion of the 'other' in the pattern of diagnosis. This has meant that the 'observed deviant' - the patient - not only is exotic but is also the 'other', making it difficult to place the diagnosis in the appropriate cultural context. It is important to reiterate that patterns of psychiatric diagnosis are not just ethnocentric but are also androcentric.

Prince \& Tcheng-Laroche (1987) emphasise that four facets of culture-bound syndromes must be taken into account when studying them: these are accidents of geography (i.e. a disorder may be present in some cultures but not in others for geographical rather than social reasons); designation (some illnesses are considered culture-bound simply because they happen to have local names); epidemiological differences (global prevalence rates, variations in gender ratios and age at onset may be used in assigning culture-bound status); and lastly that symptom differences themselves do not add to the differentiation of diagnosis. They illustrate this by using somatisation disorder as an example; clusters of illnesses across cultures have similar symptoms but are called by different names. In this review we aim to use some of these facets to illustrate the inherent problems of culture-bound syndromes.

Simons (1987), commenting on the paper by Prince $\&$ Tcheng-Laroche (1987), remarked: " "folk illness" may be a preferred term compared with "culture-bound syndrome" but to our mind this would still give it a second-class status differentiating it from a "professional illness", . Our contention is that symptoms, syndromes and their management must be embedded in local cultures in order to help clinicians.

\section{Culture-bound syndromes and diagnostic classifications}

Both ICD-10 (World Health Organization, 1992) and DSM-IV (American Psychiatric
Association, 1994) have been amended to incorporate culture as a factor in the diagnosis of psychiatric conditions. These formulations are explicitly committed to taking a theoretically neutral position with regard to aetiology as well as an explicitly descriptive approach regarding symptoms, and may well confound reliability (Hughes, 1985).

Wig (1994) makes a persuasive case that in international diagnostic systems even conditions prevalent within the European context, such as bouffée délirante (chronic interpretative delusional psychosis) in France, are not generally recognised. $\mathrm{He}$ cautions that separately categorising culture-bound syndromes will not necessarily improve the management of these cases in the country's health services. Littlewood (1996) argues that reasons for abandoning culture-bound syndrome as an entity include the option that all psychiatric patterns are culture-bound, and as culture itself has become a recognised element within general psychiatric theory, culturebound patterns will become an afterthought. Other reasons he puts forward for abandoning the concept are that a distinction between identifiable and discrete culture-bound syndromes is far from clear; phenomenological and epidemiological data are lacking; and that patterns of Western behaviour (which may be culturebound) have been included in DSM-IV categories. He points out that in the face of globalisation (and industrialisation) these syndromes are likely to disappear in an increasingly homogeneous world culture.

Bottero (1991) illustrated the ethnocentricity of the culture-bound syndrome as described by Obeyesekere (1985), who argued that Western concepts of depression may be seen as culture-bound, and that traditional doctors from the Indian subcontinent may relate weight loss in depression to nocturnal emission and diagnose dhat or 'semen-loss anxiety', a diagnosis that would appear alien to Western clinicians. Obeyesekere (1985) obviously intended to show that Western clinical concepts of depression are an example of culture-bound diagnosis. Bottéro (1991) argued that this type of explanation, often used to support an anthropological critique of psychiatry (Weiss, 1986; Kleinman, 1988), relates more to a 'pleasant sophism' than a rigorous demonstration. Bottéro (1991) emphasised that semen-loss anxiety is as universal as depression but the presentations and symptoms do differ. In this paper we present some historical and phenomenological data from Western and Eastern countries and some epidemiological data from the Indian subcontinent to illustrate both the universality of the symptoms, and the cultural context. We then argue that the reasons for abandoning culturebound syndromes as a category are many.

Wintrob (1996) feels that Hughes (1996) is justified in pointing out the psychiatric profession's wish to avoid comprehensive assessment and classification of the numerous strange-sounding, difficult-tocomprehend conditions known as culturebound syndromes. The very diversity of these syndromes requires consideration of the perennial issue of defining normality.

\section{Study objectives}

The purpose of this overview is to assert that it is the traditional models of distress and the cultural context that are important. The loss of semen is wrapped up in men's perception of their masculinity, thus the hypochondriacal, anxiety and depressive symptoms become subsumed in the major visible 'pathology' of semen loss. Our argument in this paper is that cultural context colours these symptoms and that such a context has been reported in the historical documents as well. Our study had two objectives: to gather information on studies (clinical and empirical) of dhat syndrome and review the literature, and to extract information on historical data in different countries at different periods. The hypothesis was that symptoms of semen loss and accompanying anxiety would be reported in a variety of cultures.

\section{METHOD}

An electronic search was made using the terms SEMEN LOSS ANXIETY, DHAT, CULTURE BOUND SYNDROMES of Medline, Psycinfo and EMBASE with the aim of identifying peer-reviewed papers. This was followed by hand searching of the books and papers referenced in the databased literature. The original papers were then obtained for analysis. The data were collected and analysed using a standardised pro forma. Not all information is available for every study, reflecting the heterogeneity of the sample and the methods.

\section{RESULTS}

The studies listed in Table 1 are those that collected information from clinical 


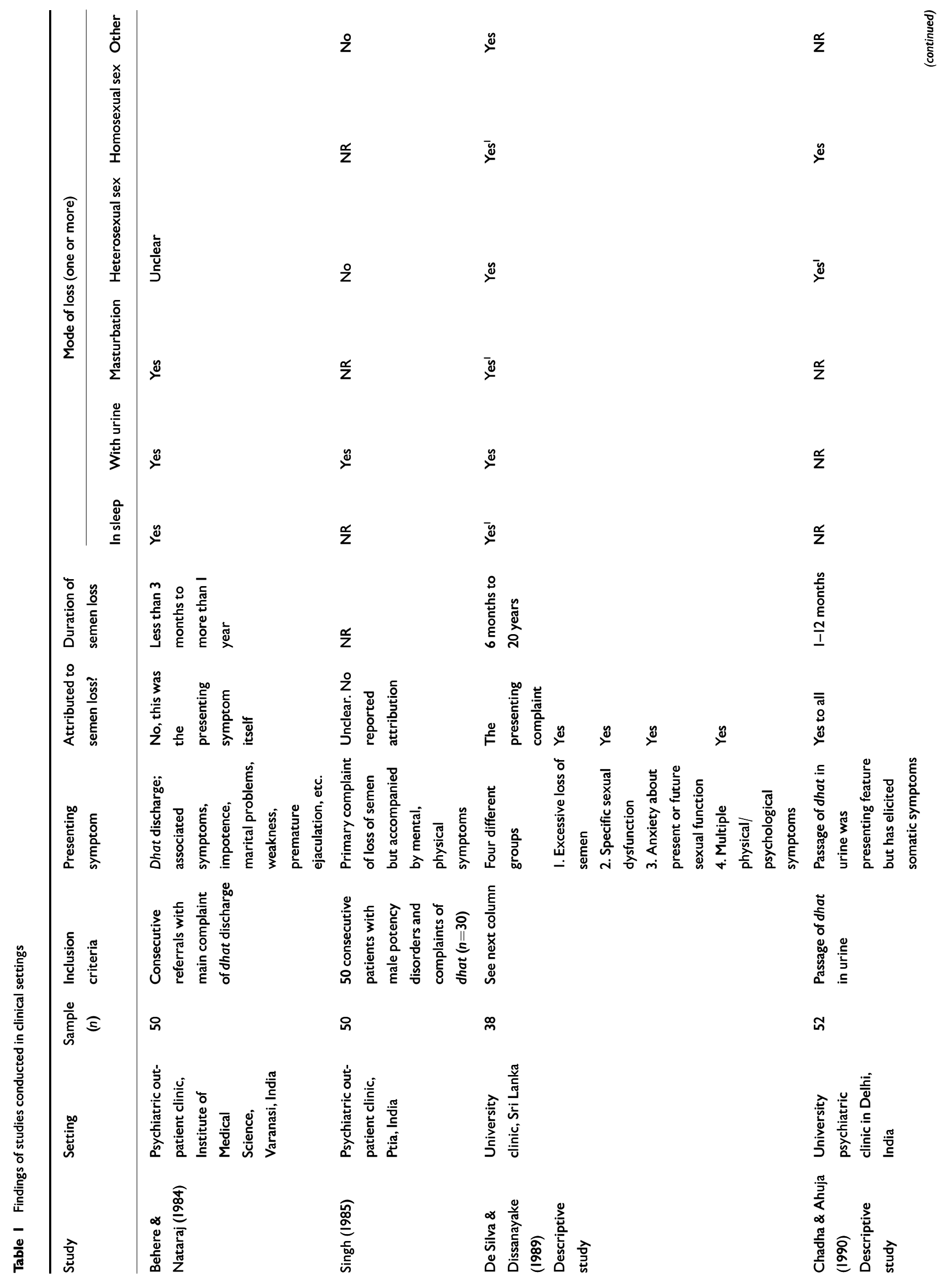




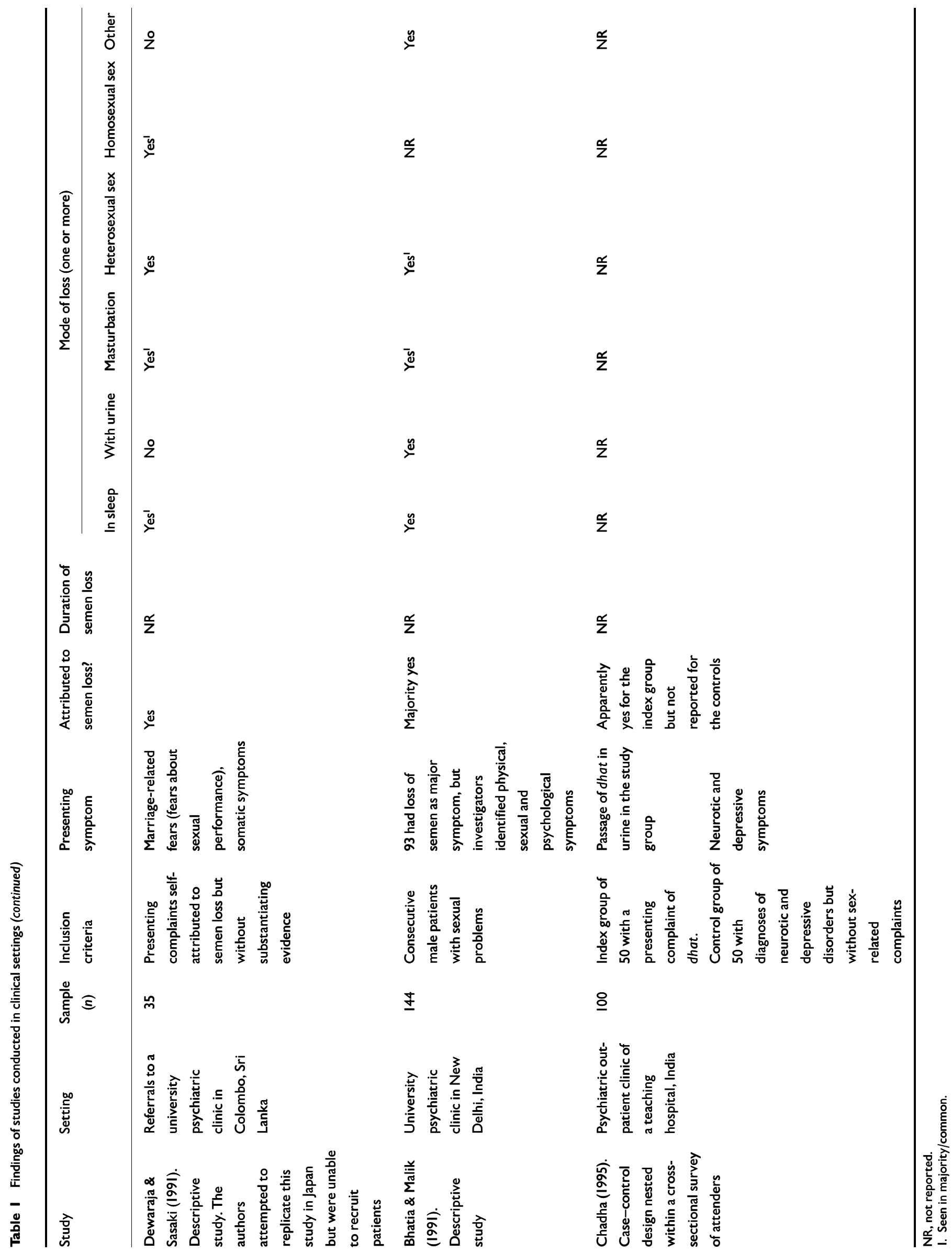


populations. Some of the studies reported whether the patients attributed their symptoms to semen loss, whereas in others it was the presenting symptom itself. Common presenting problems were hypochondriacal, depressive or anxiety symptoms. In some studies patients presented with depression and anxiety, and dhat was seen as an accompanying symptom.

The historical perspectives and development of beliefs about semen loss in some cultures are set out in Table 2 .

\section{Semen-loss anxiety in the Indian subcontinent}

Dhat derives from the Sanskrit word dhatu meaning 'metal', and also 'elixir' or 'constituent part of the body'. First described in Western psychiatric texts by Wig (1960), dhat comprises vague somatic symptoms of fatigue, weakness, anxiety, loss of appetite, guilt and sexual dysfunction attributed by the patient to loss of semen in nocturnal emissions, through urine and masturbation. The symptoms of semen-loss anxiety are well known in Indian historical writing. In Ayurvedic texts which are dated between the 5th millennium $\mathrm{BC}$ and the 7 th century $\mathrm{AD}$ the process of semen production is described thus: food converts to blood, which converts to flesh, which converts to marrow, and the marrow is eventually converted into semen. It is said that it takes 40 days for 40 drops of food to be converted to one drop of blood, 40 drops of blood to one drop of flesh, and so on (Bhugra \& Buchanan, 1989). In the individual psyche, therefore, semen starts to take on an overwhelming importance. These notions frighten the individual into developing a sense of doom if a single drop of semen is lost, thereby producing a series of somatic symptoms (Chadha \& Ahuja, 1990).

These ideas of semen loss and consequent anxiety are not confined to India; they have been reported from Sri Lanka and other parts of the subcontinent as well. Fear of semen loss and resulting problems is so strong that cures are advertised by vaids and hakims everywhere - on walls, on television, in newspapers and on roadside hoardings.

Malhotra \& Wig (1975) called dhat a 'sex neurosis of the Orient'. In an intriguing and unusual study from urban Chandigarh, they selected a random sample of 175 males aged $30-50$ years and used a case vignette to explore attitudes towards semen loss, and its causation and management. A significant proportion of the respondents agreed that semen loss was harmful and their reasons varied. Interestingly, 30\% favoured no intervention. Almost a quarter $(22.5 \%)$ advocated psychological and behavioural persuasion by relatives and friends, such as avoiding bad company, masturbation and erotic literature. A small proportion suggested dietary intervention, and $6 \%$ recommended marriage as the treatment. The study demonstrated that respondents belonging to social class I discussed sex freely when compared with lower social classes, and were less likely to see physical causes for semen loss. People in social class IV were more likely than any other group to see nocturnal emission as abnormal and least likely to see psychological persuasion as a mode of treatment. They concluded that susceptible individuals react to the belief system of semen loss. This seeking of medical intervention and the number of practitioners providing it confirm the individual's belief that there are physical reasons for the complaint, which need to be addressed.

Most of the rest of the studies from the Indian subcontinent related to clinical

Table 2 Historical perspective and development of beliefs related to 'semen loss'

\begin{tabular}{|c|c|c|}
\hline Authority & Period & Comments \\
\hline Agnivesa & $? 1500 \mathrm{BC}$ & Charaka Samhita: An Indian Treatise on Medicine (see below) \\
\hline Susruta & ? & $\begin{array}{l}\text { Susruta Samhita: An Indian Treatise on Surgery. The traditional Ayurvedic knowledge of Agnivesa and Susruta was } \\
\text { systematised and edited into these two texts between } 600 \text { BC and AD } 100 \text { (samhita means 'collection'). Semen is the } \\
\text { most concentrated, perfect and powerful bodily substance. Its preservation guarantees health and longevity }\end{array}$ \\
\hline Hippocrates & $? 460-377$ вс & Diseases II: semen supplies the form to the human body \\
\hline Aristotle & $384-322$ вс & 'Sperms are the excretion of our food, or to put it more clearly, as the most perfect component of our food' \\
\hline Galen & AD I30-20I & $\begin{array}{l}\text { Involuntary loss was termed 'gonorrhoea': 'it robs the body of its vital breath'; 'losing sperm amounts to losing the vital } \\
\text { spirits'; exhaustion, weakness, dryness of the whole body, thinness, eyes growing hollow, are the resulting symptoms }\end{array}$ \\
\hline Celsus & $\mathrm{Ca} A D 50$ & 'It results in death due to consumption' \\
\hline Esquirol & $1772-1840$ & 'One of the most common cases of melancholia and dementia and also commonly suicide' \\
\hline Tissot & $1728-1797$ & $\begin{array}{l}\text { 'Losing one ounce of sperm is more debilitating than losing forty ounces of blood', in Treatise on the Diseases Produced } \\
\text { by Onanism. His tenet was that debility, disease and death are the outcome of semen loss }\end{array}$ \\
\hline Maudsley & $1835-1918$ & Semen loss, especially if it occurs through masturbation, results in serious mental illness \\
\hline Beard & $1839-1883$ & $\begin{array}{l}\text { 'One of the commonest explanations of neurasthenia is wastage of sexual energy, often in the form of nocturnal } \\
\text { emissions (involuntary emissions)', in A Practical Treatise on Nervous Exhaustion }\end{array}$ \\
\hline Freud & $1856-1939$ & $\begin{array}{l}\text { 'Neurasthenia in males is acquired at puberty and becomes manifest in the patient's twenties. Its source is } \\
\text { masturbation, the frequency of which parallels that of male neurasthenia'. Freud opposes Steckel's view that semen loss } \\
\text { has no pernicious effect on brain functioning }\end{array}$ \\
\hline The Lancet & |840-|843 & $\begin{array}{l}\text { Editorial and articles by G. Dangerfield and W. H. Ranking: } \\
\text { 'On physical disability, mental impairment and moral degeneration caused by seminal loss' } \\
\text { 'The symptoms, pathology, causes and treatment of spermatorrhoea' } \\
\text { 'Spermatorrhoea, or the involuntary discharge of the seminal fluid' }\end{array}$ \\
\hline
\end{tabular}


populations. Often dhat was described and diagnosed as a separate entity and many authors did not give the associated psychiatric diagnosis. Thus, sometimes the syndrome is seen and recognised as a culturebound syndrome. Our contention is that this reflects a historical approach; looking at some of the detailed data, it appears that the syndrome is accompanied by easily and clinically recognisable common mental disorders, and that its descriptions abound in other cultures (European and Western) as well.

Chadha \& Ahuja (1990) reported on 52 patients who had volunteered passage of dhat in the urine as their presenting complaint; more than three-quarters were said to have accompanying hypochondriacal symptoms, although the descriptions do not make clear whether the diagnosis of hypochondriasis was made by the patient or the clinician, or what specific criteria were used to define such hypochondriasis. Interestingly, they reported that seven patients (who did not have hypochondriasis) had 'pure' dhat syndrome. Our contention is that it is possible that this concern with dhat itself is a hypochondriacal preoccupation. Bhatia \& Malik (1991) from the same centre in North India reported that of 144 consecutive patients attending a sexual dysfunction clinic, 93 presented with passing dhat. When these 93 patients were assessed with Hamilton Rating Scales and assigned to ICD-9 diagnostic categories, a significant number had one or more somatic symptoms, of which weakness was the most common. A third reported sexual problems, and half scored above 7 on the Hamilton Rating Scale for Depression. Nearly a third received no psychiatric diagnosis. These authors reported 'pure' dhat syndrome in 60 patients $(42 \%)$.

Chadha (1995), in a case-control design study, compared those presenting with dhat with controls who had neurotic disorders. He defined dhat in the urine as dhat syndrome, although not all sufferers from dhat syndrome acknowledge loss through urine. Nearly half were reported to have depressive disorder, $18 \%$ had anxiety disorder and $32 \%$ had somatoform disorders - the figures for controls were $54 \%, 30 \%$ and $16 \%$ respectively, which reflect the source of data collection for the controls. Thus, the validity of diagnosis and associated psychiatric diagnosis can be questioned. Similar findings of depression in $52 \%$ and anxiety disorders in $16 \%$ of cases had been previously reported by Singh (1985) from another part of northern India.
In an interesting study from Sri Lanka, De Silva \& Dissanayake (1989) observed that in their cohort of 38 men recruited from a clinic where they had presented with sexual dysfunction semen loss was given as a major causative factor by the men themselves. These men believed that excessive loss of semen led to sexual dysfunction and physical symptoms and thus was harmful. A majority of individuals reported continuing loss of semen over a period ranging from 6 months to 20 years. More than half were found to have somatic symptoms; $53 \%$ received a diagnosis of anxiety, $40 \%$ of hypochondriasis and $5 \%$ of stress reaction. The sample size is small but it indicates the presence of psychological and somatic symptoms to be significant. Similar findings have been reported among Bangladeshi men in the UK (Clyne, 1964).

Dewaraja \& Sasaki (1991) too collected data from the same clinic in Sri Lan$\mathrm{ka}$, and of 35 patients attributing their symptoms to loss of semen half had somatic symptoms and a third had sexual deficiencies. These authors attempted to replicate the findings in Japan but were not able to do so. They also conducted a survey of beliefs of undergraduates in Sri Lanka and Japan. Using an 18-item questionnaire they found that Sri Lankan students were more likely to believe in semen loss.

\section{Semen-loss anxiety in China}

Wen \& Wang (1980) define shen-k'uei as vital or kidney deficiency. In classical Chinese medicine shen (kidney) is the reservoir of vital essence in semen (ching) and $k^{\prime} u e i$ signifies deficiency. A form of sexual neurosis is associated with excessive semen loss due to frequent intercourse, masturbation, nocturnal emission or passing of white turbid urine which is believed to contain semen. Young people who think they might be suffering from it become anxious and panicky, and complain of somatic symptoms (with no organic cause) such as dizziness, backache, fatiguability, weakness, insomnia, frequent dreams and physical thinness. All these signs and symptoms have been acknowledged by individuals deemed to be suffering from dhat syndrome.

Described historically by $\mathrm{Ku}-\mathrm{Wu}$ Chen (1939) the Chinese concept of semen-loss anxiety is also related to koro (see below), hypersexuality and impotence. Yap (1965) reported similar symptoms among Cantonese patients in Hong Kong. Tseng (1973) suggested that as semen is seen as the essence of energy its excretion produces weakness. Similar symptoms were reported among Chinese populations in the UK (Haslam, 1980) and in Malaysia (Tan, 1969).

In China, there are beliefs that women have the ability to steal vital fluid from men and this loss of semen can lead to disease (Bottéro, 1991). Weakness in Chinese people connotes loss of vital energy ( $q i$ or ch'i), and excessive loss of semen through sexual intercourse or masturbation creates anxiety because semen is said to contain jing (the essence of qi), which when lost produces weakness (Kleinman, 1988). Yap (1965) posits that a healthy exchange of yin and yang in sexual intercourse maintains a balance. Following masturbation, nocturnal emission or homosexual intercourse, yang would be lost but without corresponding gain of $y i n$ and the resulting imbalance leads to disease. This has been associated with epidemics of koro-another culture-bound syndrome in which the individual holds the belief that his penis is shrinking into his body and disappearing (Yap, 1965; Rin, 1966; Tseng et al, 1988).

Kleinman (1982) reported that more than three-quarters of patients presenting with neurasthenia in Taiwan attributed their symptoms wholly or partially to organic causes. His earlier notion of explanatory models (Kleinman, 1980) in understanding the patient's perspective of aetiology, course, management and outcome is a useful one.

The Chinese concept of shanjing shuairuo (neurasthenia) is said to have erectile impotence as one of its key symptoms (Lee \& Wong, 1995), but it is not clear what the direction of causal effect is. Lee (1999a) argues that the imbalance of vital energy $q i$ leads to the symptoms, which represents an epistemological counterinstance to the Western ontological model of disease. Lee $(1999 b)$ points out that, as a result of social upheavals, the concept of shanjing shuiairuo is changing and being contested, and clinicians are reconstituting it as the popular Western diagnosis of depression, which may reflect a modernist view.

Taoist techniques in ancient China were based on the principle that seminal essence was located in the lower part of the male abdomen, and they aimed to increase the amount of life-giving seminal essence (ching) by sexual stimulus while at the same time avoiding possible loss (Bullough, 1976). It was essential that the woman reach orgasm in intercourse so that the 
man would receive her yin essence; the more yin essence he received without giving out his precious male substance the greater his strength would become, and this could be achieved through coitus reservatus keeping the penis in the vagina but avoiding orgasm. Another technique was to practise buan ching pu nao (making the ching return to nourish the brain), suggesting that this method and positive thinking would cause seminal essence to ascend and rejuvenate other parts of the body. Masturbation for men was seen as leading to a loss of vital essence. Manipulation of genitals without orgasm was encouraged, but involuntary emissions were viewed with concern; these were thought to be caused by fox spirits and to lead to weakness in men.

Wen \& Wang (1980) studied 87 patients attending a urology clinic in Taiwan, and found that 23 had sexual neurosis with shen-k'uei syndrome and four-fifths of the remaining 64 patients blamed their problems on masturbation. More than 23 cases of shen-k'uei came from the lower socioeconomic classes and all reported masturbation or nocturnal emission and were anxious, depressed and hypochondriacal. These authors compared shen-k'uei with prameha reported from Sri Lanka by Obeyesekere (1976), and acknowledged that the similarities between the two conditions were great. They point out that these conditions are universally occurring diseases for which illness behaviours, experiences and beliefs are culture-specific. Tan (1980) too related these symptoms to hypochondriasis. These symptoms and their explanations are culturally embedded and have been reported widely from the continent of Asia. Engelhardt (1974) suggested that medicine culturally constructs categories of behaviour that fit previous moral or legal categories: thus, the creation of $d$ hat and other culture-bound syndromes has to be seen in the historical and legal constructs of the time.

\section{Semen-loss anxiety \\ in Western cultures}

From the times of Hippocrates and Aristotle, semen has been considered extremely important for the healthy functioning of the individual. Greeks in ancient times saw masturbation as a natural outlet for men lacking opportunity for sexual intercourse. Galen (c. 130-201), following the example of Aristotle, stated:

'Certain people have an abundant warm sperm which incessantly arouses the need of excretion: however, after its expulsion, people who are in this state experience a languor at the stomach orifice, exhaustion, weakness, and dryness of the whole body. They become thin, their eyes grow shallow' (Galen, 1963 reprint).

This description is not dissimilar from that of the modern dhat syndrome. Before the Christian era, Jewish writers too acknowledged that the depositing of semen anywhere else than the vagina was debilitating and that to become ritually pure after such emission a short period of continence was normally required. Masturbation was regarded as a crime deserving the death penalty, according to one Talmudic writer. A fear of loss of semen was well known, but why this loss was so feared is not entirely clear (Bullough, 1976). Bullough suggested that a loss might imply the failure of men's duty to procreate and replenish the earth; unexpected or inappropriate loss of semen might lead to reduction in the size of the tribe, thereby making it more vulnerable.

In many Western European cultures masturbation has been prohibited on religious grounds. Even nocturnal emissions were seen as sinful and required three nights of an hour-long standing vigil for expiation if the sinner had been receiving an adequate diet of beer and meat. Those on poor diets were merely required to sing psalms or undertake extra work. Apparently it was assumed that a person who had been fasting would have less control over his bodily processes, hence an involuntary nocturnal emission would be less sinful.

European attitudes to non-heterosexual behaviour and loss of semen varied in the Middle Ages: see Bullough (1976) for a further discussion. However, for our purposes, Tissot's writings in the 18th century provide an interesting overview. $\mathrm{He}$ believed that even with an adequate diet the body could waste away through diarrhoea, blood loss and seminal emission. Semen caused the beard to grow and muscles to thicken, and its involuntary loss weakened men. Frequent intercourse was dangerous in itself, but the most dangerous loss of semen occurred when the individual lost it through unnatural means, of which masturbation was the most debilitating. Such waste of semen could lead to cloudiness of ideas and madness, decay of bodily powers, acute pains in the head, pimples on the face, eventual weakness of the power of generation (as indicated by impotence, premature ejaculation, gonorrhoea, priapism and tumours of the bladder) and intestinal disorder. Again, this is not dissimilar to the symptoms and concerns of patients who present with dhat. Tissot gave scientific credibility to the Western hostility to sex. The similarities between the hostility to sex then prevalent in the West and that now current in India are uncanny. Formerly a society with a positive view of sex, Hindu culture has now become obsessed with the idea that the main purpose of sex is procreation rather than pleasure.

The emerging middle classes of the 18th century embraced Tissot's ideas with great enthusiasm, and sexual purity became a way of distinguishing themselves from the sexual promiscuity of the nobility and the lower social classes. Tissot (1766) led the Western world into an age of masturbatory (or, shall we say, dhat) insanity. Alhough Tissot's work did not reach the USA until 1832, his influence was apparent in the writings of Benjamin Rush, who is often credited as the father of American psychiatry. Rush believed that all diseases could be caused by debility of the nervous system and propounded that careless indulgence in sex would lead to seminal weakness, impotence, dysuria, tabes dorsalis, pulmonary consumption, dyspepsia, dimness of sight, vertigo, epilepsy, hypochondriasis, loss of memory, myalgia, fatuity and death (Rush, 1812). An American physician, Sylvester Graham, advocated Graham flour (unbolted wheat) and 'Graham crackers' as a cure for debility, skin and lung disease, headaches, nervousness, and weakness of the brain - much of which he blamed on sexual excess (Graham, 1834). The cause was orgasm due to abuse or misuse of sexual organs; overindulgence in sex caused languor, lassitude, muscular relaxation, general debility and heaviness, depression of spirits, loss of appetite, indigestion, faintness and sinking at the pit of the stomach, increased susceptibility of skin and lungs, feebleness of circulation, chilliness, headache, melancholy, hypochondria, hysterics, feebleness of senses, impaired vision, loss of memory, epilepsy, insanity and apoplexy. Like the Hindu perceptions, Graham believed that the loss of an ounce of semen was equivalent to the loss of several ounces of blood; therefore every time a man ejaculated he lowered his life force and exposed his system to diseases. These attitudes are not dissimilar to attitudes held by patients presenting with dhat syndrome and mentioned in Ayurvedic texts.

In France, Lallemand (1839) too was concerned with involuntary loss of semen, 
which would lead to insanity. William Acton, an English physician, encouraged men to engage in sex infrequently so that they could not lose their energy through prolonged sexual activity; he maintained that the worst kind of seminal emission was by masturbation (Acton, 1871). Another American, Kellogg (of breakfast cereal fame), believed that the nervous shock accompanying the exercise of the sexual organs was the most profound to which the nervous system was subject, and produced a long list of symptoms, both physical and psychological:

'the dangers were terrible to behold, senile genital excitement produced intense congestion and led to cultural irritation, priapism, piles and prolapsus of rectum, atrophy of the testes, varicocoele, nocturnal emissions and general exhaustion' (Kellogg, 1882).

His cereals were developed as a panacea for the ills of masturbation. Every loss of semen was regarded as equivalent to the loss of 4 ounces of blood, and although the body could eventually replace the loss it took time for it to recuperate (Hunter, 1900).

In Britain in the 1840s, articles on the involuntary discharge of seminal fluid dominated The Lancet. Dangerfield suggested that, as a result of involuntary discharge,

'the patient complains of weakness, restlessness and listlessness, his manners are shy and nervous with a remarkable timidity and indisposition to answer questions, his complexion is generally pale, slightly emaciated, he gradually loses memory, has dull pain, and feeling of weakness especially in the lower extremities along with fatigue. On further investigations, the physician will find that he has been afflicted for some time with seminal emissions during sleep accompanied by libidinous dreams' (Dangerfield, 1843).

In a comprehensive review, Darby (2001) suggested that male circumcision was advocated as a cure for spermatorrhoea (as well as masturbation) and this was the testing ground on which regular medical practitioners sought to establish their credentials and to demarcate themselves from quacks. $\mathrm{He}$ argued that William Acton in Britain and George Beaney in Australia were representatives of the battle for professional turf and the medical right to manage all the functions of the body. Unfortunately for the regular doctors, until circumcision became an option the treatments they offered differed little from those of their rivals.

Colonialism imposed this 19th-century medical orthodoxy in Australia (Walker, 1985, 1987, 1994); the theory that any seminal loss weakened the system led to demands by the colonists for treatments for semen loss. Darby (2001) cautions that it is not possible to draw a hard and fast line between regular doctors and quacks: the former exhibited plenty of evidence of ignorant faddism and eccentricity, whereas the latter frequently offered more humane and less damaging treatments. George Beaney, who graduated from Edinburgh and settled in Melbourne in 1857, published extensively on the damaging effects of spermatorrhoea, suggesting that semen was more precious than blood, and that treatments for spermatorrhoea were effective if victims avoided the 'quacks'. Spermatorrhoea was defined as an abnormal emission of seminal fluid:

'of all the diseases to which man is liable there are few others which induce so much mental anxiety as this and it embitters all the victim's [sic] social relations and subjects him to the harrowing reflection that he is the object of the taunts and jeers of those about him' (Beaney, 1870).

Masturbation was both a specific form of spermatorrhoea and its cause, and it ruined the nervous equilibrium of the sexual system. According to Beaney, the consequences of masturbation and spermatorrhoea included inflammation of the urethra, bladder irritation, disturbed sleep, erotic dreams, confusion of mind, vertigo, wakefulness, depression, tuberculosis, epilepsy and impotence. Darby (2001) suggested that Beaney's views were religious tub-thumping and were not scientific. However, it is possible that Beaney merely reflected the prevalent public view of spermatorrhoea and semen-loss anxiety. In making his views more culturally specific to Australian manhood, Beaney makes the point that the relatively free and easy life of the Antipodes and the more relaxed social structure lead to increasing sexual precocity among children, thus magnifying the threat to Australian manhood. Recommended treatments included sitz baths, alcohol and chemical compounds such as potassium bromide and phosphorus, and application of electricity to the nervous system. Gradually circumcision came to be seen as a treatment for these sexual urges.

Thus it seems that in the 19th century anxieties about semen loss were widespread even in what was then a remote outpost of the British Empire. Whether the clinicians were reflecting their own anxieties or those of their patients remains a moot point. What is clear is that semen-loss anxiety is neither a new condition nor confined to the Orient. The scientific backing of morality and the prohibition of sexual activity continued unabated in the 19th and early 20th centuries; their impact on 'patients' is uncertain, but there is little doubt that much of the writings of Graham, Kellogg and others were directed at the general population. There must have been a demand for such advice, because most of these monographs went into several editions and were translated into several European languages. The similarities between their writings and the present-day descriptions of dhat are remarkable.

\section{DISCUSSION}

There are problems with the data we have presented. Empirical and clinical findings are reported for south Asia, where dhat is seen as a significant clinical problem, although we have described some historical and cultural contexts. For Western countries and Australia, the data we have presented are historical.

Our contention is that with industrialisation and urbanisation, the anxiety about semen loss in the West diminished, and the same is likely to happen in southern Asia as well. If we understand dhat as a culture-bound syndrome, the historical evidence indicates that it was prevalent in Europe, USA and Australia in the 19th century. In those countries it might have disappeared in response to changes in social and economic factors, whereas it is still prevalent in southern Asia. We believe that the universality of symptoms of anxiety (in this case secondary to feared or actual loss of semen) has to be acknowledged. Our initial hypothesis has been partially proved.

Although we found that symptoms of semen-loss anxiety were reported from a range of cultures, we also found that in the West these symptoms were mainly reported during the 19th century. We believe that although there are discrepancies in the data from modern-day India, and only descriptions exist of the symptoms in 18th- and 19th-century Western societies, it proves that dhat syndrome is not culture-bound and it is certainly not an exclusive exotic neurosis of the Orient. Furthermore, it is our contention that dhat and dhat syndrome as described in research from the Indian subcontinent is not always a homogeneous entity, and although syndromes by definition are heterogeneous the symptoms described are more likely to be psychological or psychosomatic even 
though their attribution to dhat may be culturally influenced.

We welcome the amendments to DSMIV in that it now offers an outline for cultural formulation in which multiaxial diagnostic assessments are supplemented by a systematic review of the individual's cultural background and the role of the cultural context in the expression and evaluation of symptoms and dysfunction, together with the effect that cultural differences might have on the relationship between the individual and the clinician. Cultural identity of the individual and cultural explanations of the individual's distress - as well as factors related to psychosocial environment, levels of functioning and the relationship between the individual and clinician - are important. If all these factors are taken into account and used seriously in diagnoses then the scope for culture-bound syndromes becomes even more limited, even though this category is retained in DSM-IV.

Prince \& Tcheng-Laroche (1987) pleaded that culture-bound syndrome status should not be assigned on the basis of the geographic distribution of the illness, nor on the basis of a local 'label', notions of cause or epidemiological features. More importantly, they felt that the meaning of illness for both individuals and their culture should not be confused with syndrome descriptions or used as criteria for international classification. Beiser (1987) considers that some conditions will never fit into the illness discourse and must remain exotic or unclassifiable. We feel that it is possible to categorise these conditions, provided the emphasis is on pathology in its true biopsychosocial context, allowing the diagnostic flexibility. Kleinman's caution of category fallacy became much more relevant in this context (Kleinman, 1980).

We acknowledge the assertion by Tseng (2001) that cultures do influence psychopathology - through pathogenic, pathoselective, pathoplastic, pathoelaborating, pathofacilitating and pathoreactive effects but we believe that the interaction between the individual and the culture is extremely complex. Even if the culture is pathofacilitatory or pathoreactive, the individual's disorder can be and will be influenced by other factors such as personality traits, peer and family support available to the individual, and alternative explanations of the experience.

Society and culture will no doubt dictate pathways into help-seeking and care, and the resources-economic, political and human - that are allocated. Tseng (2001) proposes that culture-bound syndromes be sub-grouped according to the six impacts of culture mentioned above; but we maintain that the time has come to abandon this category altogether and focus on multi-axial systems that include cultural factors in aetiology and management. Dhat provides an illustration that, when looked at carefully, these conditions transcend cultural boundaries, and such variations should be seen in the cultural context.

We believe that attribution patterns and explanatory models need to be studied regarding semen-loss anxiety in different cultures to confirm our hypothesis. We accept that loss of semen is a shared belief reported from certain societies; it may be that this is reported because the clinicians and the researchers are aware of it and therefore willing to ask questions regarding such an attribution. Beiser (1987) cautions that the general thrust of the argument for the closure of the concept of culture-bound syndrome is premature. We disagree, and believe that the time is right to look at the classificatory systems, their purpose, their isolationist tendencies and their emphasis on disease rather than illness. Wig's concept of simple, bias-free and clinically useful classification (Wig, 1994) remains a distant dream. Kapur (1987) introduces the Eastern spiritual tradition to emphasise that nature cannot be reduced to discrete building blocks or categories, but is rather a web of interconnecting relationships. Kapur's view is that a classification system based only on symptoms and signs would be useful if there were a one-to-one relationship between the syndrome, the processes at various levels and management strategies. This is not so, however, and it is not possible to trigger in our minds the appropriate meaning at whatever level we wish to operate. We agree with Kapur's assertion that the classification of psychiatric disorder should allow itself to be open to all experiences, expressions and meanings, and users should remain open to the realisation that there is no absolute truth to any of these.

\section{ACKNOWLEDGEMENTS}

A.S. is funded by the Wellcome Trust. D.B. has accepted hospitality and lecture fees from Eli Lilly, Janssen-Cilag, Lundbeck and Sanofi-Synthelabo.

\section{REFERENCES}

Acton, W. (187I) The Functions and Disorders of the Reproductive Organs in Childhood, Youth, Adult Age, and
Advanced Life Considered in Their Physiological, Social and Moral Relations. London: Churchill.

American Psychiatric Association (1994) Diagnostic and Statistical Manual of Mental Disorders (4th edn) (DSM-IV). Washington, DC: APA.

Arieti, S. \& Meth, J. (1959) Rare, unclassifiable, collective and exotic syndromes. In American Handbook of Psychiatry (ed. S. Arieti), pp. 546-563. New York: Basic Books.

Beaney, G. J. (1870) Spermatorrhoea in its Physiological, Medical and Legal Aspects. Melbourne: Walker.

Beard, G. M. (1905) A Practical Treatise on Nervous Exhaustion. New York: E. B. Treat.

Behere, P. B. \& Nataraj, G. S. (1984) Dhat syndrome: the phenomenology of a culture bound sex neurosis of the Orient. Indian Journal of Psychiatry, 26, 76-78.

Beiser, M. (1987) Commentary. Culture Medicine and Psychiatry, II, 29-34.

Bhatia, M. S. \& Malik, S. C. (1991) Dhat syndrome. A useful diagnostic entity in Indian culture. British Journal of Psychiatry, 159, 691-695.

Bhugra, D. \& Buchanan, A. (1989) Impotence in ancient Indian texts. Sexual and Marital Therapy, 4, 87-92.

Bhugra, D. \& Jacob, K. S. (1997) Culture bound syndromes. In Troublesome Disguises (eds D. Bhugra \& A. Munro), pp. 296-334. Oxford: Blackwell.

Bottéro, A. (1991) Consumption by semen loss in India and elsewhere. Culture, Medicine and Psychiatry, I5, 321-359.

Bullough, V. L. (1976) Sexual Variance. Chicago, IL: University of Chicago Press.

Chadha, R. K. (1995) Dhat syndrome: is it a distinct clinical entity? Acta Psychiatrica Scandinavica, 91, 136-139.

Chadha, C. \& Ahuja, N. (1990) Dhat syndrome. A sex neurosis of the Indian subcontinent. British journal of Psychiatry, I56, 577-579.

Clyne, M. B. (1964) Indian patients. Practitioner, 193 195-199.

Dangerfield, G. N. (1843) The symptoms, pathology, causes and treatment of spermatorrhoea. Lancet, $i$, $211-216$

Darby, R. (200I) A source of serious mischief. In Understanding Circumcision (eds G. C. Denniston, F. M. Hodges \& M. F. Milos), pp. 153-197. New York: Kluwer Academic.

De Silva, P. \& Dissanayake, S. A. W. (1989) The loss of semen syndrome in Sri Lanka. A clinical study. Sexual and Marital Therapy, 4, 195-204.

Devereux, G. (1956) Normal and abnormal. In Some Uses of Anthropology (eds J. B. Casgrande \& T. Gladwin). Washington, DC: Anthropological Society.

Dewaraja, R. \& Sasaki, Y. (1991) Semen loss syndrome. A comparison between Sri Lanka and Japan. American Journal of Psychotherapy, 45, 14-20.

Engelhardt, H.T. (1974) The diseases of masturbation values and concepts of disease. Bulletin of the History of Medicine, 48, 234-248.

Galen (1963 reprint) On The Passion and Error of The Soul (trans. P.W. Hawkins). Columbus, OH: Ohio State University.

Graham, S. (1834) A Lecture to Young Men on Chastity. Boston, MA: Pierce.

Haldipur, C.V. (1980) The idea of cultural psychiatry: a comment on the foundations of cultural psychiatry. Comprehensive Psychiatry, 21, 206-2II. 
Haslam, M.T. (1980) Medicine and the Orient: Shen-k'uei syndrome. British Journal of Sexual Medicine, 7. $31-36$

Hughes, C. C. (1985) Glossary. In Culture Bound Syndromes (eds R. C. Simons \& C. C. Hughes), pp. 465-505. Dordrecht: Reidel.

Hughes, C. C. (1996) The culture bound syndrome and psychiatric diagnosis. In Culture and Psychiatric Diagnosis: A DSM-IV Perspective (eds !. Mezzich, A. Kleinman, H. Fabrega, et al), pp. 298-308. Washington, DC: APA.

Hughes, C. C. \& Wintrob, R. M. (1995) Culture bound syndromes and the cultural context of clinical psychiatry. In Review of Psychiatry (eds J. M. Oldham \& M. Riba) pp. 565-597. Washington, DC: APA.

Hunter,W. J. (1900) Manhood: Wrecked and Rescued. New York: Health Culture.

Kapur, R. L. (1987) Commentary. Culture, Medicine and Psychiatry, II, 43-48.

Kellogg, J. H. (1882) Plain Facts for Old and Young. Burlington, VT: Senger

Kleinman, A. (1980) Patients and their Healers in the Context of Culture. Berkeley, CA: University of California Press.

Kleinman, A. (1982) Neurasthenia and depression Culture, Medicine and Psychiatry, 6, II7-190.

Kleinman, A. (1988) The Illness Narratives, p. 23. New York: Basic Books.

Ku-Wu Chen, D. (1939) A Clinical Text of Chinese Medicine. Taipei: General Press.

Lallemand, M. (1839) On Involuntary Seminal Discharges (trans.W. Wood). Philadelphia, PA: Waldier.

Lee, S. (1999a) The vicissitudes of neurasthenia in Chinese societies: where will it go from the ICD-I0? Transcultural Psychiatry Research Review, 3I, 153-172.

Lee, S. (1999b) Diagnosis postponed: Shenjing Shuaruo and the transformation of psychiatry in post Mao China. Culture, Medicine and Psychiatry, 23, 349-380.

Lee, S. \& Wong, K. C. (1995) Rethinking neurasthenia the illness concepts of shenjing shuaruo among Chinese undergraduates in China. Culture, Medicine and Psychiatry, 19, 91-111.

Littlewood, R. (1996) Cultural comments on culture bound syndromes: I. In Culture and Psychiatric Diagnosis: A DSM-IV Perspective (eds J. Mezzich, A. Kleinman, $\mathrm{H}$ Fabrega, et al), pp. 309-312. Washington, DC: APA.

Littlewood, R. \& Lipsedge, M. (1985) Culture bound syndromes. In Recent Advances in Clinical Psychiatry (ed. K. Granville-Grossman), pp. 105-142. Edinburgh: Churchill Livingstone.

Malhotra, H. K. \& Wig, N. N. (1975) A culture bound sex neurosis in the Orient. Archives of Sexual Behaviour 4, 519-528.

Mezzich, J. E., Kleinman, A., Fabrega, H., et al (1996) Introduction. In Culture and Psychiatric Diagnosis: A DSM-IV Perspective (eds J. E. Mezzich, A. Kleinman, H. Fabrega, et al), pp. xvii-xxiii. Washington, DC: APA

Murphy, H. B. M. (1976) Notes for a theory of latah. In Culture Bound Syndromes (ed.W. Lebra), pp. 3-21. Honolulu: University of Hawaii Press.

Murphy, H. B. M. (1977) Transcultural psychiatry should begin at home. Psychological Medicine, 7, 369-37I.

Obeyesekere, G. (1976) The impact of Ayurvedic ideas on the culture and the individual in Sri-Lanka. In Asian Medical Systems (ed. C. Leslie), pp. 201-226. Berkeley, CA: University of California Press.

\section{CLINICAL IMPLICATIONS}

- Clinicians should embed psychiatric symptoms in their cultural context.

- Culture-bound syndromes are neither exotic nor rare, and often span different cultures.

- Researchers should not rely only on epidemiological data.

\section{LIMITATIONS}

- Historical data may be scanty and biased.

- Culture-bound syndromes such as dhat do not explain somatisation disorders.

- Culture-bound syndromes may reflect a culturally specific idiom of distress.

A. SUMATHIPALA, MD, MRCPsych, Section of Epidemiology, Institute of Psychiatry, London, UK S. H. SIRIBADDANA, MD, Sri Jayawerdenpura General Hospital, Nugegoda, Sri Lanka; DINESH BHUGRA PhD, FRCPsych, MPhil, Section of Cultural Psychiatry, Institute of Psychiatry, London, UK

Correspondence: Professor Dinesh Bhugra, Section of Cultural Psychiatry, PO25, Institute of Psychiatry, London SE5 8AF, UK

(First received I April 2003, final revision 21 July 2003, accepted 31 July 2003)

Obeyesekere, G. (1985) Depression, Buddhism and work of culture in Sri Lanka. In Culture and Depression (eds A. Kleinman \& B. Good), pp. 134-152. Dordrecht: Reidel.

Prince, R. \& Tcheng-Laroche, F. (1987) Culture bound syndromes and International Disease classifications. Culture, Medicine and Psychiatry, II, 3-20.

Rin, H. (1966) Two forms of vital deficiency syndrome among Chinese male mental patients. Transcultural Psychiatry Research Review, 3, 19-214.

Rush, B. (1812) Medical Inquiries and Observations upon the Diseases of the Mind. Philadelphia, PA: Kimber \& Richardson.

Simons, R. C. (1987) Commentary. Culture, Medicine and Psychiatry, II, 2I-28.

Singh, G. (1985) Dhat syndrome revisited. Indian Journal of Psychiatry, 27, 119-221.

Tan, E. S. (1969) The symptomatology of anxiety in Malaysia. Australia and New Zealand Journal of Psychiatry, 3, $271-276$

Tan, E. S. (1980) Culture bound syndromes. In Normal and Abnormal Behaviours in Chinese Culture (eds A. Kleinman \& T.-Y. Lin), pp. 37I-386. Dordrecht: Reidel.

Tissot, S. A. (1766) Onanism, or a Treatise on the Diseases Produced by Onanism (trans. A. Hume). London: Pridden.

Tseng, W.-S. (1973) The development of psychiatric concepts in traditional Chinese medicine. Archives of General Psychiatry, 29, 569-575.

Tseng, W.-S., Mo, K. M., Hsu, J., et al (1988) A sociocultural study of koro epidemics in Guangdong, China. American Journal of Psychiatry, 145, 1538-1543.

Tseng, W.-S. (200I) Handbook of Cultural Psychiatry. San Diego, CA: Academic Press.

Walker, D. (1985) Continence for a nation: seminal loss and national vigour. Labour History, 48, I-14.
Walker, D. (1987) Modern nerves, nervous moderns: notes on male neurasthenia. Australian Cultural History 6, 49-63.

Walker, D. (1994) Energy and fatigue. Australian Cultural History, 13, 164-178.

Weiss, M. (1986) History of psychiatry in India: toward culturally and historiographically informed study of indigenous traditions. Samiksa, 4, 519-528.

Wen, T.-K. \& Wang, C.-L. (1980) Shen-k'uei syndrome a culture-specific sexual neurosis in Taiwan. In Normal and Abnormal Behaviour in Chinese Culture (eds A. Kleinman \& T.-Y. Lin), pp. 357-369. Dordrecht: Reidel.

Wig, N. N. (1960) Problems of the mental health in India. Journal of Clinical and Social Psychiatry (India), 17 48-53.

Wig, N. N. (1994) An overview of cross-cultural and national issues in psychiatric classification. In Psychiatric Diagnosis: A World Perspective (eds J. E. Mezzich, Y. Honda \& M. C. Kastrup), pp. 3-10. New York: Springer.

Wintrob, R. M. (1996) Cultural comment on culture bound syndromes. In Culture and Psychiatric Diagnosis: A DSM-IV Perspective (eds J. Mezzich, A. Kleinman, $\mathrm{H}$. Fabrega, et al), pp. 313-320. Washington, APA.

World Health Organization (1992) Internationa Statistical Classification of Diseases and Related Health Problems (ICD-I0). Geneva: WHO.

Yap, P. M. (1962) Words and things in comparative psychiatry with special reference to exotic psychosis. Acta Psychiatrica Scandinavica, 38, 157-182.

Yap, P. M. (1965) Koro: a culture bound depersonalisation syndrome. British Journal of Psychiatry, III, 43-45.

Yap, P. M. (1969) The culture bound syndromes. In Mental Health Research in Asia and The Pacific (eds W. Cahil \& T. Y. Lin), pp. 33-53. Honolulu: East-West Centre Press. 